\title{
Enhanced fatigue behaviour in quenched and tempered high strength steel by means of double surface treatments
}

\author{
E. Segurado*, J. Belzunce e I. Fdez. Pariente. \\ University of Oviedo, Campus Universitario, 33203 Gijón, Spain. \\ * Corresponding author. Tel.: (+34) 985458039; (+34) 985182230 Ext. 6349 \\ E-mail address: elvirasegurado@gmail.com (E.Segurado).
}

\begin{abstract}
The aim of this study is to maximize the fatigue life of a high strength steel. For this purpose, two different kinds of double surface treatments were studied: shot peening plus vibratory finishing and shot peening plus grit blasting. First, a high intensity peening treatment was applied, with the aim of inducing a deep region submitted to high compressive residual stresses, and a second surface treatment followed, to reduce the roughness induced in the first treatment and mitigate the damage produced on the specimen surface.
\end{abstract}

The use of such double treatments was demonstrated to be a good choice to achieve high surface hardening and deep compressive residual stress profiles and to minimize surface defects. The fatigue life of the steel was greatly enhanced following the application of both double surface treatments. A vibratory treatment applied for 24 hours after the application of a previous shot peening treatment was able to increase the average fatigue life of the single shot peened samples almost sevenfold, but a much greater fatigue enhancement was produced using grit blasting for only 60 seconds. Anyway, both second treatments are able to remove the damaged surface layer produced in the first high intensity shot peening treatment.

The obtained results also revealed that an appropriate combination of surface treatments (shot peening+secondary treatment) avoided the initiation of cracks at the surface of the specimens under cyclic bending loads. Instead, crack initiation took place beneath the compressive residual stress field, induced in alumina inclusions that acted as stress concentrators.

KEYWORDS: Fatigue, double surface treatments, shot peening, vibratory finishing, grit blasting, residual stresses, structural steels. 


\section{Introduction}

There are different surface modification treatments able to improve the fatigue performance of metallic alloys, which are widely applied in industry. Roll burnishing, deep rolling, shot peening, laser peening, ultrasonic peening have been employed among others for this purpose. The fatigue properties of the treated components are improved because these surface modification treatments can ameliorate their surface integrity, which includes surface roughness and topography, microstructure and residual stresses [1].

Shot peening is a versatile cold mechanical surface treatment widely used in the automotive and aeronautical industries to improve the fatigue behaviour of metallic structural parts, notched machine elements, and welded details for its effectiveness, flexibility, and cost/benefit ratio. It consists in projecting very hard, tiny, spherical balls onto the component surface with the aim of inducing surface plastic deformation. This treatment produces several effects (work hardening and compressive residual stresses in the subsurface, though also an increase in roughness and surface defects) which, if properly controlled, can provide important enhancements. In particular, it is currently used to improve the fatigue performance of components subjected to dynamic loads [24].

It is also well known that the value of the residual stress produced in the shot peening processes is dependent on different parameters, being the shot peening intensity (Almen intensity) the most important one. The Almen intensity is related to the amount of kinetic energy transferred from the shot stream to a target component during the shot peening process and is governed by the velocity, size, weight, and hardness of the shots, as well as by the angle at which the stream of shots impinges in the surface of the workpiece. The method commonly used to quantify peening intensity was introduced by Almen and Black and usually uses type A Almen strips [5]. Full procedures and specifications for measuring shot peening intensity can be found in [1]. The higher the applied shot peening intensity, the deeper the residual compressive stress field, 
although surface damage in the form of small notches or folds can also be induced [68]. The optimal peening intensity to obtain the best fatigue behaviour depends on the mechanical strength of the treated steel. For example, Aggarwal et al. [8] obtained the best fatigue performance with an Almen intensity of $17 \mathrm{~A}$ on a tempered martensitic steel with a tensile strength of $1256 \mathrm{MPa}$ and an optimum shot peening treatment of $6 \mathrm{~A}$ was obtained by Torres et al. [7] on a quenched and tempered 4340 steel with a tensile strength of $1864 \mathrm{MPa}$.

Furthermore, different authors have demonstrated the possibility of increasing the fatigue life of components using double treatments [9-11]. In essence, double treatments consist in first applying a high intensity peening treatment, with the aim of inducing a deep region submitted to high compressive residual stresses, followed by a second surface treatment, to reduce the roughness induced in the first treatment and mitigate the damage produced on the specimen surface. Shot peening, polishing, and even thermochemical treatments, as nitriding, have been employed as second treatments [12-14]. Scuracchio et al. [13] demonstrated that the use of a high intensity shot peening treatment using $0.8 \mathrm{~mm}$ shots followed by a second peening treatment with $0.3 \mathrm{~mm}$ diameter shots led to the optimal fatigue performance regarding fatigue life in a Q+T 9245 steel with a hardness of 500 HB. Cho et al. [15] applied shot peening as a pre-treatment to cause severe plastic deformation to enhance nitrogen diffusion at lower temperatures in a second nitriding treatment. Anyway, polishing is currently the usual technique employed as a second treatment $[16,17]$ : polishing benefits in surface quality outweight the disadvantage of a slight reduction in the compression residual stress layer thickness of the shot peened component, but nevertheless, it has the drawbacks of being both an expensive and slow process.

Hence, the use of other, more effective types of second surface treatments, such as vibratory finishing and grit blasting, were explored in this study. The effects of applying these second surface treatments for different times on the roughness, residual stress profile and fatigue performance of previously shot peened samples were studied in this research work and the importance of having a surface or an internal fatigue initiation location was highlighted. 


\section{Material, samples and method}

\subsection{Material}

This study was performed on a F1272 steel (equivalent to AISI 4340). This is a $0.41 \%$ carbon steel alloyed with $1.9 \%$ nickel, $0.87 \%$ chromium and $0.24 \%$ molybdenum (in weight \%). The steel was supplied in bars with a nominal diameter of $16 \mathrm{~mm}$. The bars were submitted to the following heat treatment: austenitization at $850^{\circ} \mathrm{C}$ for $45 \mathrm{~min}$, followed by water quenching and tempering at $200^{\circ} \mathrm{C}$ for $150 \mathrm{~min}$. The heat-treated steel had a tempered martensite microstructure, a yield strength of $1596 \mathrm{MPa}$, an ultimate tensile strength of $2000 \mathrm{MPa}$, a tensile elongation of $11 \%$, and an area reduction of $50 \%$.

\subsection{Samples}

After applying the aforementioned heat treatment to several steel bars of approximately $300 \mathrm{~mm}$ in length, two different types of specimens were machined: flat disks with a thickness of $10 \mathrm{~mm}$, transversally cut from the bars, and specimens for the fatigue tests. Figure 1 a) shows an image of both kinds of samples, while Figure $1 \mathrm{~b}$ ) shows the geometry and dimensions $(\mathrm{mm}$ ) of the fatigue specimens (in accordance with the ASTM E466 standard [18]). 


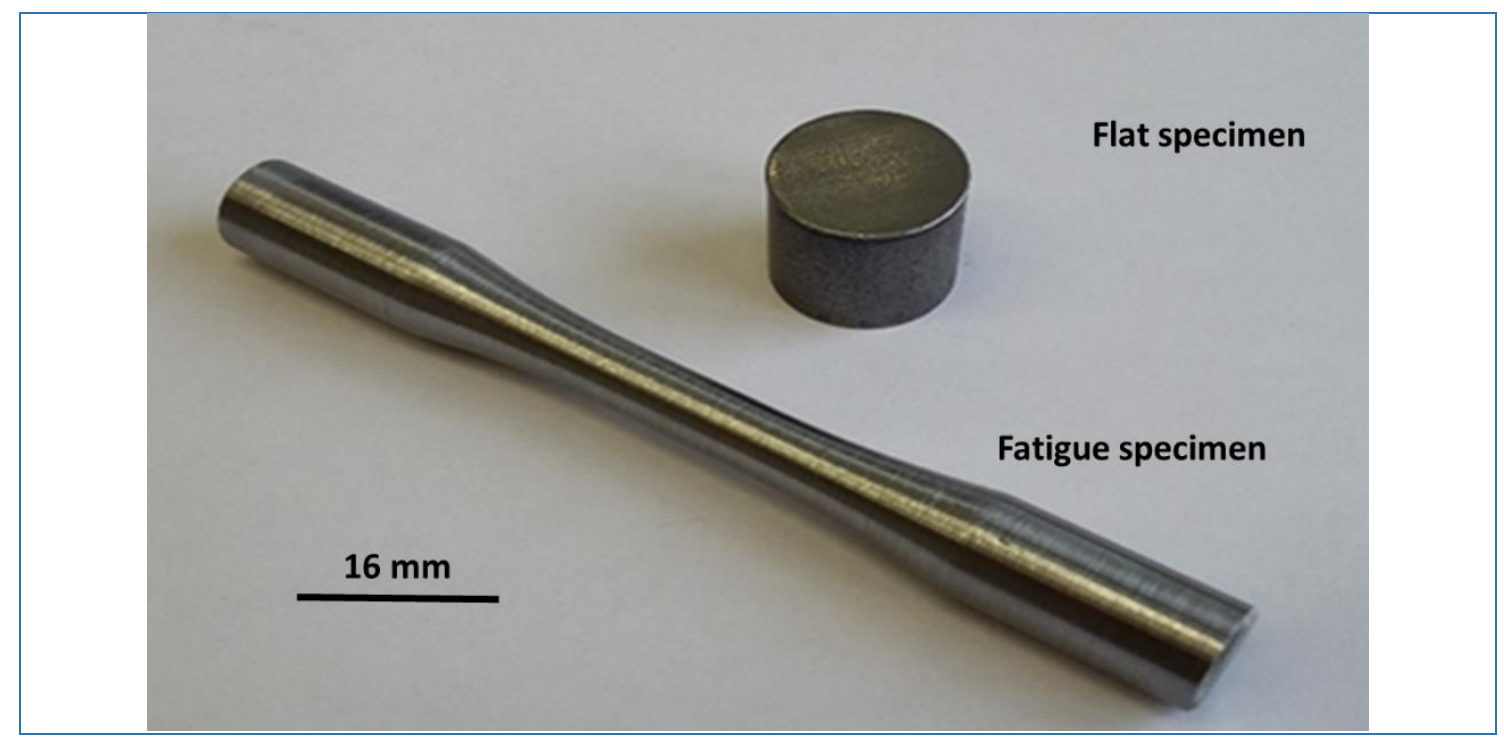

a)

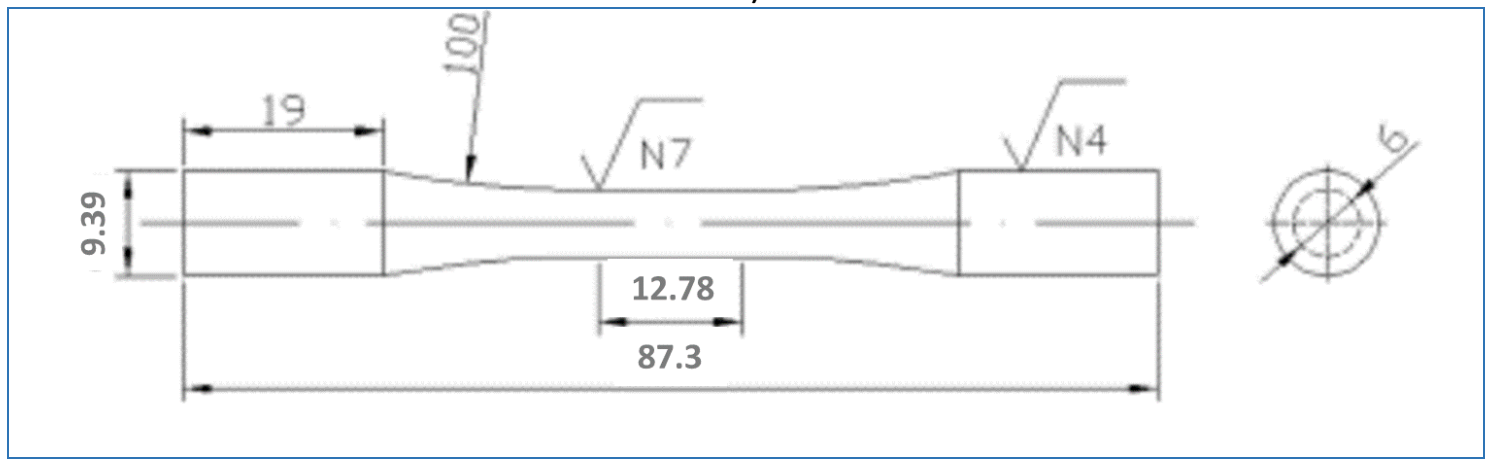

b)

Figure 1: a) Flat and fatigue specimens, b) Geometry and dimensions ( $\mathrm{mm}$ ) of the specimens for the fatigue tests

The surface treatments described below were applied to both kinds of specimens.

\subsection{Surface treatments}

Shot peening was performed by means of a direct compressed air machine using cut wire shots with rounded-off edges (CW) of $0.7 \mathrm{~mm}$ in diameter with a hardness of 670 $730 \mathrm{HV}$, under an Almen intensity of $19 \mathrm{~A}$. This treatment was applied according to SAE J442 and J443 specifications $[19,20]$. Throughout the experiments, a nozzle with $5 \mathrm{~mm}$ diameter, a distance of $240 \mathrm{~mm}$ between nozzle and workpiece, an impact angle of $90^{\circ}$, and $100 \%$ coverage were used. 
Since the samples used in the fatigue tests were rotated at a speed of one revolution per second, they were surface treated twice as long as the flat ones, because only half of the surface is continually submitted to the treatment, as can be seen in Figure 2 a).

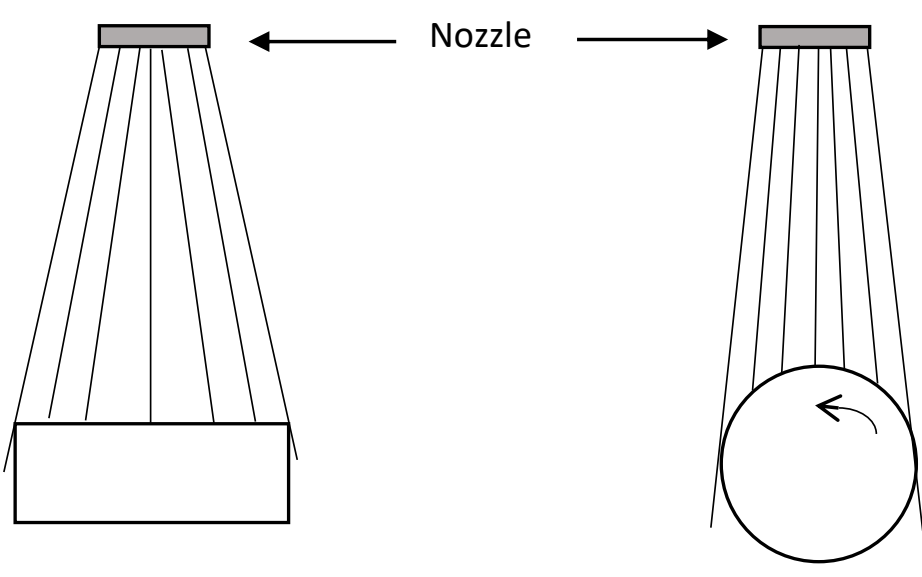

Flat sample

Fatigue sample

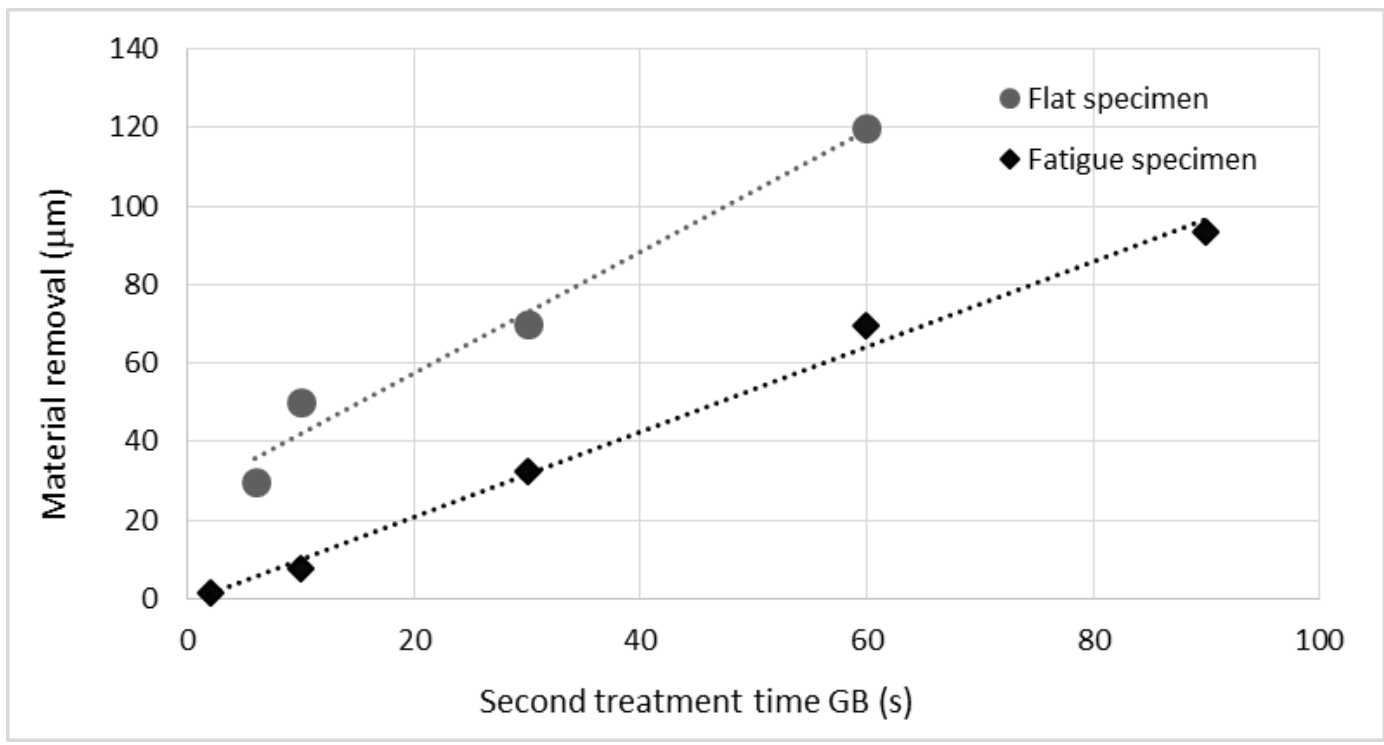

b)

Figure 2. a) Shot peening performed onto flat and fatigue specimens ; b) Material removal with grit blasting time (flat and fatigue specimens) 
Two different second treatments were subsequently applied under different processing times: vibratory finishing and grit blasting. Vibratory finishing (VF) was applied by placing the samples in a Rösler vibratory finishing machine equipped with bevelled abrasive ceramic cylinders of $10 \mathrm{~mm}$ in length and $3 \mathrm{~mm}$ in diameter (RP 03/10 ZS), using a SiC polishing paste (RSP 508 S) and water. Different processing times up to 24 hours were applied. The main reasons for the application of this treatment are to remove the damaged surface material layer and polish the specimen surface. Instead, grit blasting (GB) was applied by means of the same aforementioned direct compressed air machine used for shot peening, using alumina powder with a grit size below $0.1 \mathrm{~mm}$, an air pressure of 2 bars and, in the case of fatigue samples, they were rotated at a speed of one revolution per second. Different processing times were likewise applied. Grit blasting also removes the damaged surface material layer, though, in this case, surface roughness is directly related with grit blasting conditions, mainly with grit size and air pressure. Figure $2 \mathrm{~b}$ ) shows the effect of grit blasting time onto surface material removal from flat (static) and fatigue (rotating, 1 rps) specimens.

\subsection{Characterization techniques}

Roughness measurements, residual stress profiles and fatigue tests were used as characterization techniques following single shot peening treatment (19 A), and after the different double treatments (19 A+VF and $19 A+G B)$.

\subsubsection{Roughness}

Surface roughness was determined on the flat samples by means of a roughness tester. Average $\left(R_{a}\right)$ and maximum $\left(R_{\max }\right)$ roughness values were obtained following the ISO1302 DIN 4768 standard. The surface roughness was measured at five different positions on each sample, out of which the mean value was obtained. 


\subsubsection{Residual stress profiles}

Measurements were made on an X-Stress 3000 G3R device manufactured by Stresstech under the experimental conditions shown in Table $1[21,22]$.

Residual stress was determined by means of X-ray diffraction technique using the $\sin ^{2} \psi$ method on the flat specimens, Figure $1[23,24]$. In order to obtain the residual stress profiles, thin layers of material were progressively removed step by step by electropolishing using a mixture of $94 \%$ acetic acid and $6 \%$ perchloric acid as electrolyte, under a voltage of 40-50V. The slight stress relaxation produced by electro-polishing was also taken into account and corrected in accordance with Sikarskie [25], who has developed a method based on the Moore and Evans procedure [26]. Diffraction data were determined in three different azimuthal directions, $-45^{\circ}, 0^{\circ}$ and $+45^{\circ}$. However, as stresses are uniform in this plane, average results will be henceforth shown.

Table 1: Experimental conditions for determining residual stress

\begin{tabular}{|c|c|c|c|}
\hline Wavelength $\mathbf{K} \boldsymbol{~ ( C r )}$ & Exposure time (s) & Filter & $\varnothing$ Collimator (mm) \\
\hline $0.2291 \mathrm{~nm}$ & 20 & Vanadium & 2 \\
\hline Tilt $\Psi$ () & Background & $\begin{array}{c}\text { Rotation angle, } \boldsymbol{\phi} \\
(\mathbf{0})\end{array}$ & Fit \\
\hline 9 points between & Parabolic & $-45^{\circ}, 0^{\circ},+45^{\circ}$ & Pseudo-Voigt \\
\hline Measuring mode & Miller index (hkl) & Diffraction angle & $\begin{array}{c}\text { Elastic constant } \\
\text { E/(1+v) (GPa) }\end{array}$ \\
\hline$\chi$-modified & $(211)$ & $156.0^{\circ}$ & $168.9 \pm 2.8$ \\
& & & \\
\hline
\end{tabular}

\subsubsection{Fatigue tests}

Finally, fatigue tests were carried out on a four-point loading R. R. Moore rotating beam fatigue testing system (fully reversed loading, $R=-1$ ) at room temperature under a 
nominal frequency of $95 \mathrm{~Hz}(5700 \mathrm{rpm})$. The geometry and dimensions of the fatigue specimens were shown in Figure 1b). The maximum alternating surface stress applied was $1100 \mathrm{MPa}$ (55\% of the tensile strength of the steel). This load was selected due to the condition to be always above the fatigue limit and, in the case of the best treatments, not far from it. The number of specimens tested under each condition varied between 4 and 6 . Fatigue test results are shown as an average of all the tested samples, although individual values are also reported. Once the specimens had failed, fractographic analyses were carried out using a SEM microscope provided by an electron probe energy dispersive microanalysis to detect the origin of the fatigue crack and to determine the chemical composition of the initiation inclusion.

\section{Results}

\subsection{Shot peening along with vibratory finishing treatments}

\subsubsection{Roughness}

Table 2 shows the evolution of roughness values with the vibratory finishing treatment time. Roughness significantly decreases in a linear trend with the vibratory finishing treatment time.

Table 2. Roughness values after shot peening and vibratory finishing treatments ( \pm standard error)

\begin{tabular}{|c|c|c|}
\hline & $R_{a}(\mu \mathrm{m})$ & $R_{\max }(\mu \mathrm{m})$ \\
\hline SP 19 A & $2.3 \pm 0.2$ & $15.2 \pm 1.5$ \\
\hline SP 19 A+ 8h VF & $1.7 \pm 0.1$ & $11.5 \pm 1.9$ \\
\hline SP 19 A+ 16h VF & $1.2 \pm 0.1$ & $9.4 \pm 1.6$ \\
\hline SP 19 A+ 24h VF & $0.9 \pm 0.1$ & $8.0 \pm 1.3$ \\
\hline
\end{tabular}




\subsubsection{Residual stresses}

Figure 3 shows the residual stress profiles of the different double treatments, along with the profile corresponding to the single 19 A shot peening treatment. In order to obtain a good estimate of the layer removed in the vibratory finishing treatments, all the profiles were superimposed on the stress decay region. It can be seen that $50 \mu \mathrm{m}$ of surface layer was removed after $8 \mathrm{~h}$ of vibratory finishing, $55 \mu \mathrm{m}$ after $16 \mathrm{~h}$, and, finally, $60 \mu \mathrm{m}$ after the $24 \mathrm{~h}$ treatment.

It can also be seen that the residual stress profiles remains practically unaffected following the application of the secondary surface treatments. In fact, only the small loss of depth due to removal of material from the specimen surface is noticed.

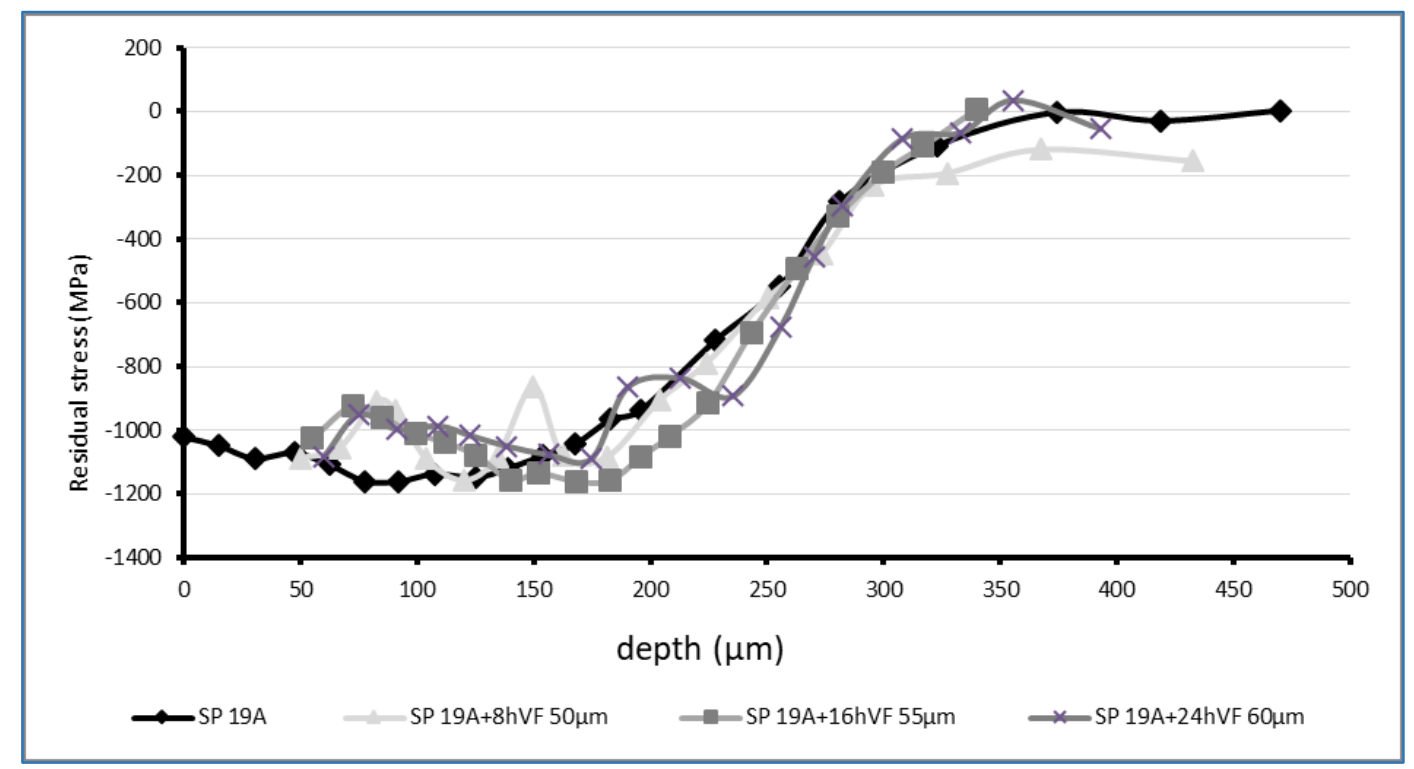

Figure 3: Residual stress profiles of SP 19 A and SP 19 A plus the different second vibratory finishing treatments (uncertainty of each measurement: $2 \%$ or $\pm 50 \mathrm{MPa}$ )

\subsubsection{Fatigue tests}

Figure 4 shows the fatigue test results obtained under a maximum alternating stress of $1100 \mathrm{MPa}$ (55\% of the ultimate tensile strength). The results obtained with non-treated specimens (NSP) and with specimens submitted to the single 19 A shot peening treatment are also included. First of all, shot peening under an intensity of $19 \mathrm{~A}$ produces an almost fourfold increase in the average fatigue life of the non-treated samples. 
Moreover, the effect on the fatigue response of shot peening along with vibratory finishing treatments is even greater. The progressive increase in fatigue life with the duration of the vibratory finishing treatment is also evidenced: the 24 hours vibratory treatment was able to increase the average fatigue life of the single shot peened samples almost sevenfold. Furthermore, four out of the five specimens had a fatigue life greater than 200000 cycles, whereas this life was not achieved with any of the samples submitted to the other treatments.

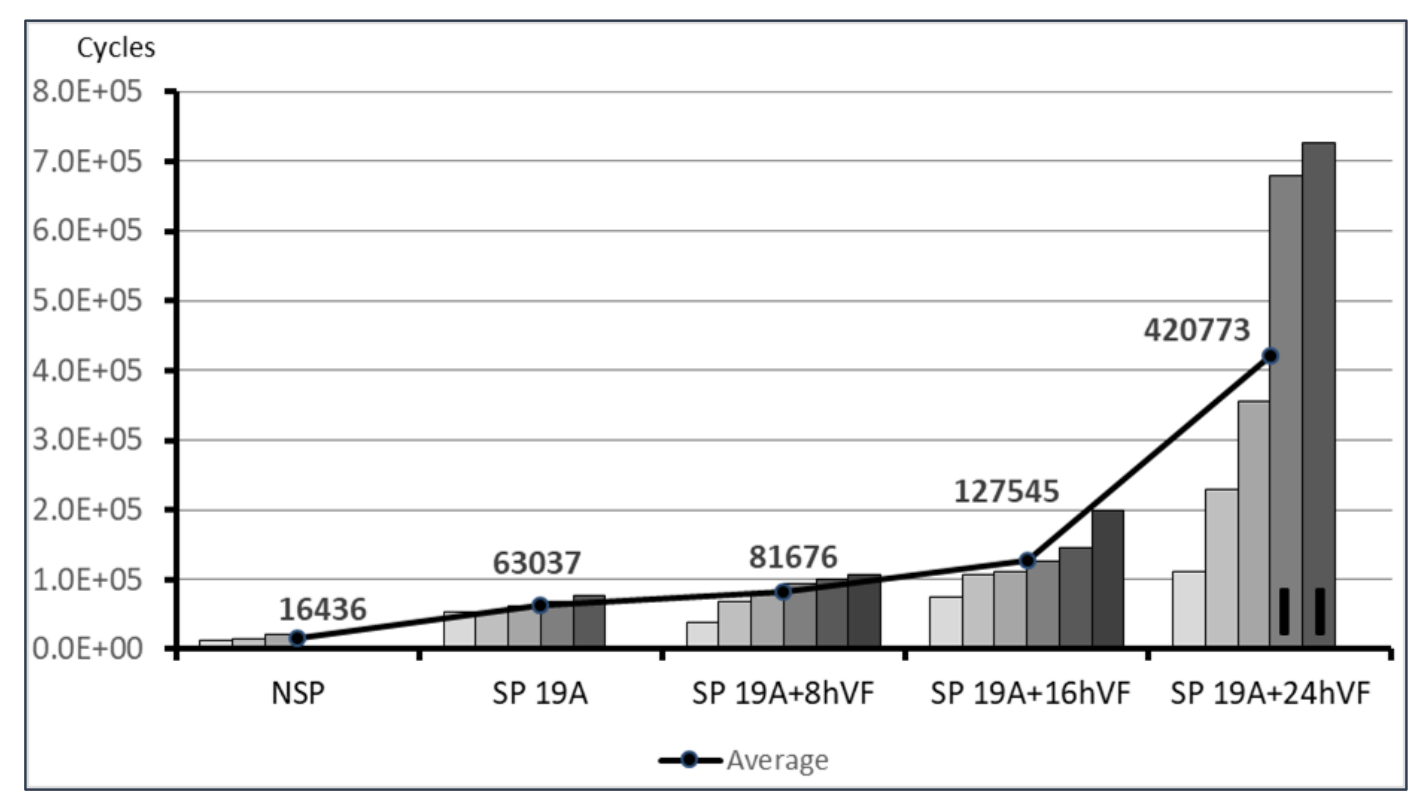

Figure 4: Fatigue life of double treated samples (SP+VF) under an alternative stress of $1100 \mathrm{MPa}$. "I" denotes internal fatigue crack initiation. Fatigue crack initiated at the surface in all the other specimens

\subsection{Shot peening along with grit blasting treatments}

\subsubsection{Roughness}

Table 3 shows the evolution of roughness values with grit blasting time. In this case, roughness decreases slightly with the grit blasting processing time until reaching uniform values at processing times larger than $30 \mathrm{~s}$.

Table 3. Roughness values after shot peening along with grit blasting treatments ( \pm standard error) 


\begin{tabular}{|l|c|c|}
\hline & $\mathrm{R}_{\mathrm{a}}(\mu \mathrm{m})$ & $\mathrm{R}_{\max }(\mu \mathrm{m})$ \\
\hline SP 19 A & $2.3 \pm 0.2$ & $15.2 \pm 1.5$ \\
\hline SP 19 A+GB-2s & $2.0 \pm 0.1$ & $14.5 \pm 0.7$ \\
\hline SP 19 A+GB-10s & $2.0 \pm 0.15$ & $15.0 \pm 1.7$ \\
\hline SP 19 A+GB-30s & $1.7 \pm 0.1$ & $12.9 \pm 1.1$ \\
\hline SP 19 A+GB-60s & $1.5 \pm 0.1$ & $12.2 \pm 1.5$ \\
\hline SP 19 A+GB-90s & $1.5 \pm 0.1$ & $12.0 \pm 1.3$ \\
\hline
\end{tabular}

\subsubsection{Residual stresses}

Figure 5 shows the residual stress profiles of the different double treatments $(S P+G B)$, along with the profile corresponding to the single 19 A shot peening treatment. As in Figure 3, profiles were also superimposed on the stress decay region in order to determine the depth of the removed surface layer. It can be seen that the surface layer removed after grit blasting applied for $6,10,30$ and $60 \mathrm{~s}$ was 30, 50, 70 and $120 \mu \mathrm{m}$, respectively.

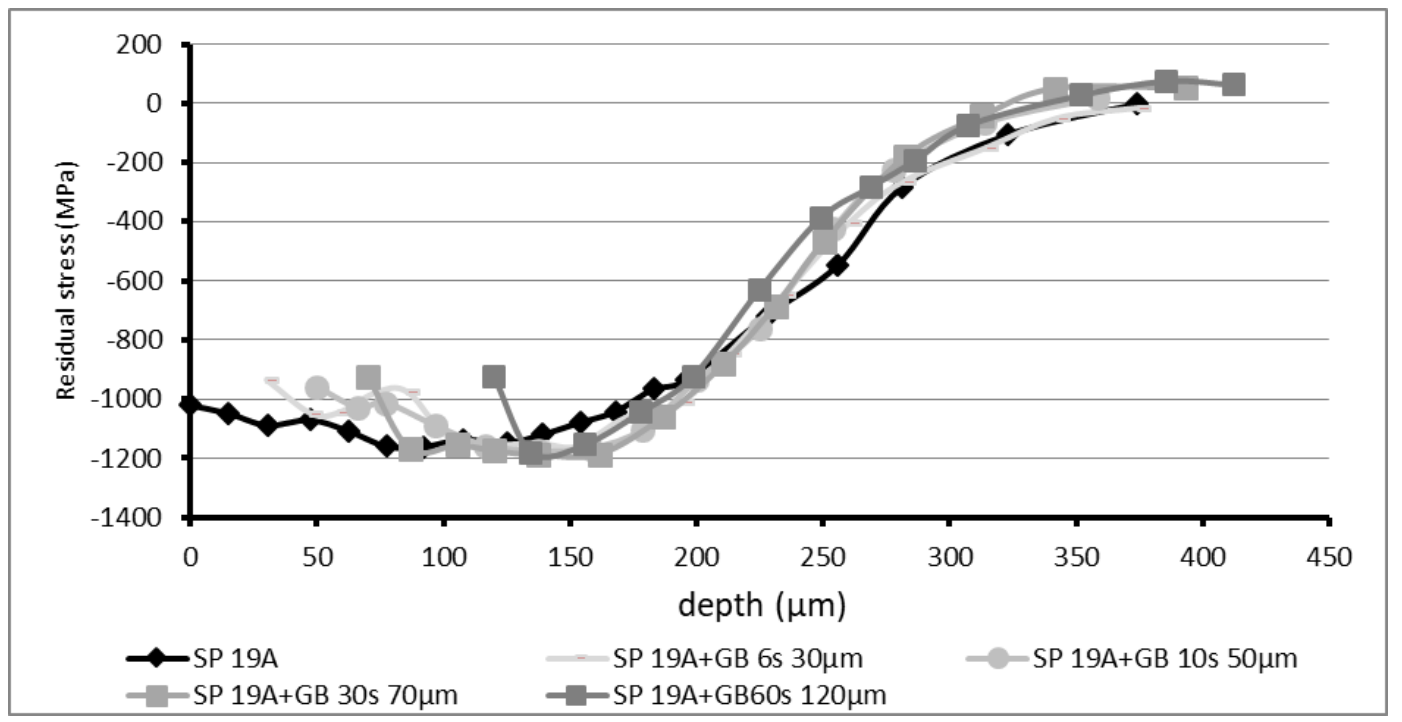

Figure 5: Residual stress profiles of SP 19 A and SP 19 A plus grit blasting treatments (uncertainty of each measurement: $2 \%$ or $\pm 50 \mathrm{MPa}$ )

Once again, as with vibratory finishing, Figure 5 shows the small effect that grit blasting has on the residual stress profile. In this case, in addition to the small surface layer 
removed by the treatment, a slight and barely significant decrease in the compressive residual stresses affecting the first $15-20 \mu \mathrm{m}$ below the surface was observed.

\subsubsection{Fatigue tests}

Figure 6 shows the fatigue test results obtained under a maximum alternating stress of $1100 \mathrm{MPa}$ (55\% of the ultimate tensile strength). The results obtained with non-treated specimens (NSP) and with specimens submitted to the single 19 A shot peening treatment are also included. It is worth noting that all the double treatments (shot peening along whith grit blasting) improved the fatigue behaviour of the single shot peening treatment.

The fatigue life increases with increasing duration of the grit blasting treatment until a maximum is attained for the $60 \mathrm{~s}$ grit blasting treatment. However, fatigue life decreases with the $90 \mathrm{~s}$ grit blasting treatment because an overly deep surface layer was removed and thus the region subjected to compressive residual stresses was reduced in excess. The $60 \mathrm{~s}$ grit blasting treatment removed a surface layer of $70 \mu \mathrm{m}$ from the fatigue specimen, which is similar to the surface layer removed in $30 \mathrm{~s}$, half the time, on the flat sample, see Figure 2 , giving rise to the highest average fatigue life (760000 cycles), which corresponds to a twelvefold increase of the average fatigue life of the single shot peened treatment. This is a very relevant enhancement of the fatigue life of this steel grade. In comparison with these results, Scuracchio et al. [13], using double shot peening treatments, only attained a $50 \%$ increase in the average fatigue life of quenched and tempered SAE 9254 steel springs, while similar effects in the fatigue life (also about a $50 \%$ increase) was produced by means of polishing treatments applied onto a previous shot peened surface on a 4340 steel [10] and also on a nickel superalloy [16]. Second peening treatments can compress and compact surface damage produced in the first high intensity peening treatment, but surface damage restoration is not fully complete. Instead, the removal of damaged material by polishing, vibratory finishing, or grit blasting can eliminate any previous damage, but only the last mechanical treatment is able to do it efficiently and quickly, as polishing and vibratory finishing require very long treating times. 


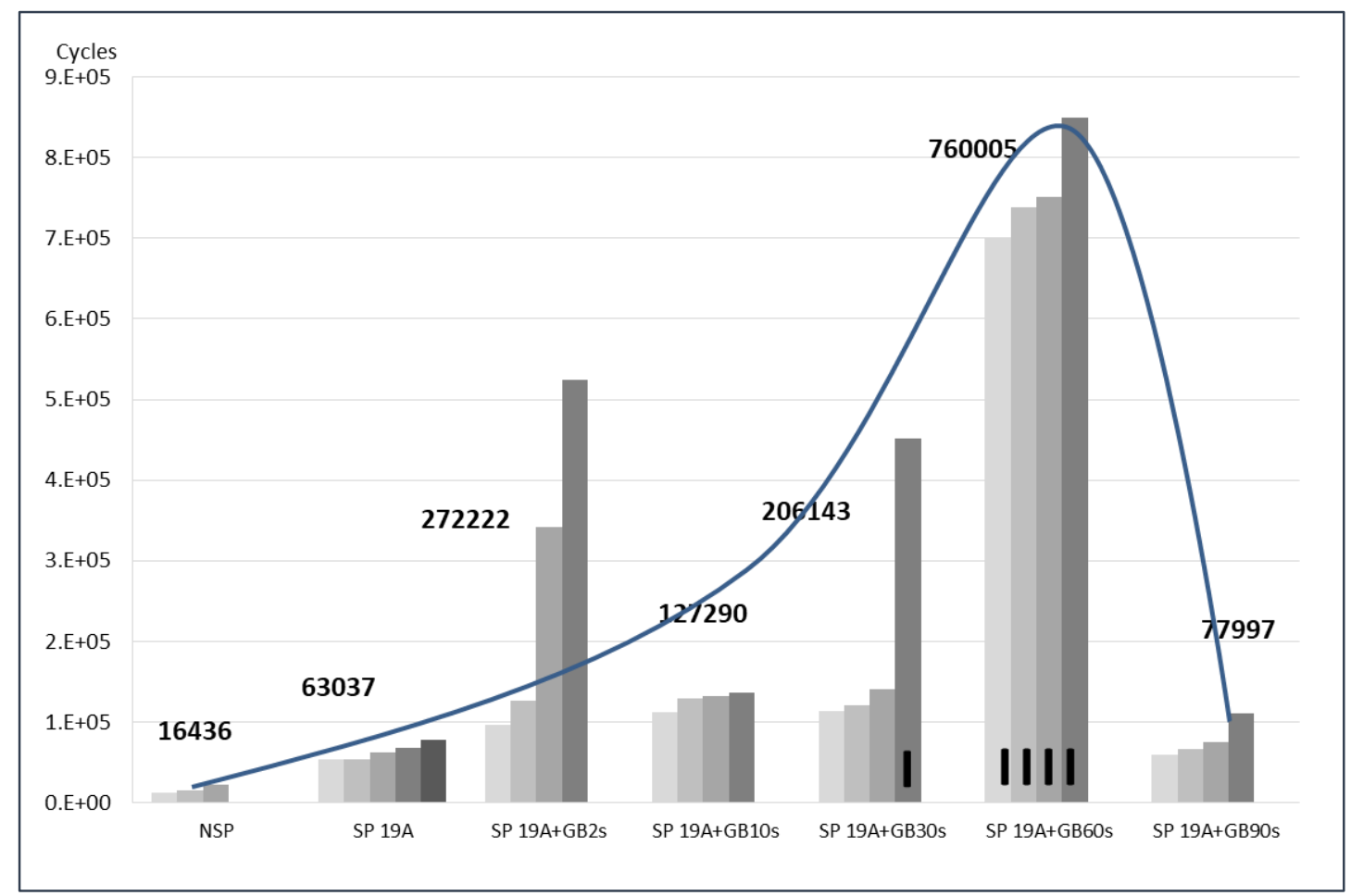

Figure 6: Fatigue life of shot peening along with grit blasting $(S P+G B)$ treatments under an alternative stress of $1100 \mathrm{MPa}$. "I" denotes internal fatigue crack initiation. Fatigue crack initiated at the surface in all the other specimens

\section{Discussion}

Double surface treatments, consisting in applying a high intensity shot peening treatment, $19 \mathrm{~A}$ (with the aim of producing a deep region submitted to high compressive residual stresses) followed by a second surface treatment to reduce roughness and mitigate the surface damage induced by the first treatment, proved to be highly suitable in enhancing the fatigue performance of the high strength quenched and tempered 4340 steel grade.

Grit blasting treatments are much better than vibratory finishing in terms of efficiency, as the optimization of vibratory finishing requires at least 24 hours to remove a damaged depth of around $60 \mu \mathrm{m}$ (longer times could increase fatigue life even more, but are ruled out for economic reasons), while the optimal duration of grit blasting treatment is only $60 \mathrm{~s}$. This second treatment, performed with fine alumina powder (grit size below 0.1 $\mathrm{mm})$, was able to remove an average surface layer depth of around $70 \mu \mathrm{m}$ on the 
specimens used in the fatigue tests. In this way, most of the surface defects induced in the previous high intensity shot peening process were efficiently removed. It is also worth noting that the work hardened depth provided by the shot peening $19 \mathrm{~A}$ treatment in this steel grade was $0.3 \mathrm{~mm}$ [27] and this value is not much different from the depth submitted to compressive residual stresses $(0.35 \mathrm{~mm}$, Figure 3$)$.

It should be noted that two out from the five fatigue specimens of 19 A+VF24h, Figure 4, and all the 19 A+GB60s fatigue specimens, Figure 6 (specimens with the best fatigue performance on both series), exhibited internal initiation of the fatigue crack, although the maximum applied stress in our fatigue experiments (bending tests) always acted on the specimen surface. One of these fracture surfaces, observed under the scanning electron microscope, can be seen in Figure 7.

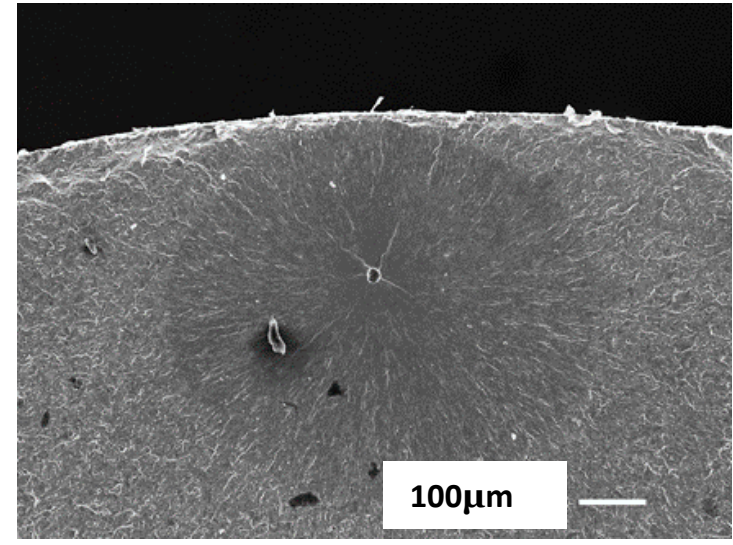

a)

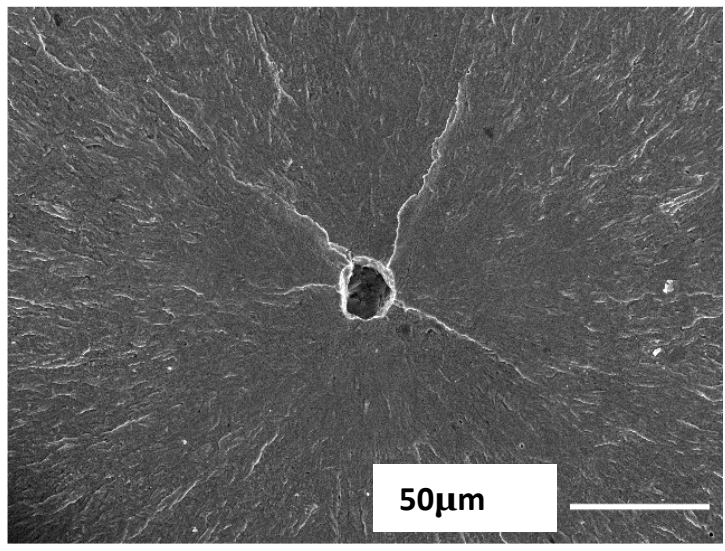

b)

Figure 7: Fracture surface in SP 19 A+GB60s; a) internal crack initiation b) initiation at an alumina inclusion

The location of fatigue damage initiation, which took place at a depth of $250 \mu \mathrm{m}$ from the surface, is clearly visible in this figure. This depth corresponds to a point where the residual compressive stress had been reduced to almost zero in this specimen (SP $19 \mathrm{~A}$ +GB30s, see Figure 5). Internal fatigue damage initiation took always place under the stress concentration provided by the presence of a hard non-deformable alumina inclusion. 
A fatigue crack initiates internally when the stress concentration factor due to surface defects generated by shot peening is minimized by means of an appropriate second treatment. Figure 8 shows the surface topography observed in the 19 A shot peened treatment, and also on the double treatments, SP19A+24hVF, and SP19 A +GB60s. High intensity shot peening produces surface defects, such as folds, notches and small cracks (Figure $8 \mathrm{a}, \mathrm{b}$ ), and the application of second treatments (VF and GB) progressively removes the damaged surface layer generated in the first high intensity shot peening treatment. In the case of grit blasting, the surface topography of these samples reproduces the geometry of the fine, angular alumina projectiles (Figure $8 \mathrm{c}, \mathrm{d}$ ) and after vibratory finishing treatments a partially polished surface is observed (Figure $8 \mathrm{e}, \mathrm{f}$ ). Hence, fatigue life is related to the extension and depth of surface defects induced in the first high intensity shot peening treatment, and surface roughness is not relevant in this case as it is not able to detect the existence of such defects.

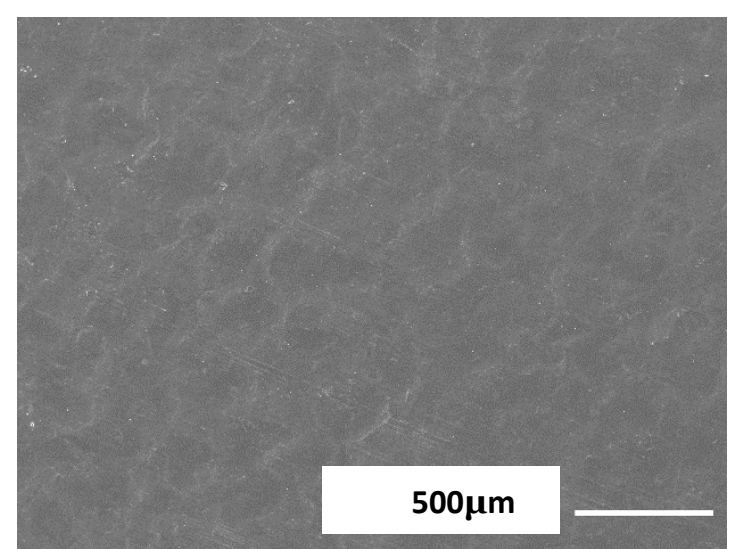

a)

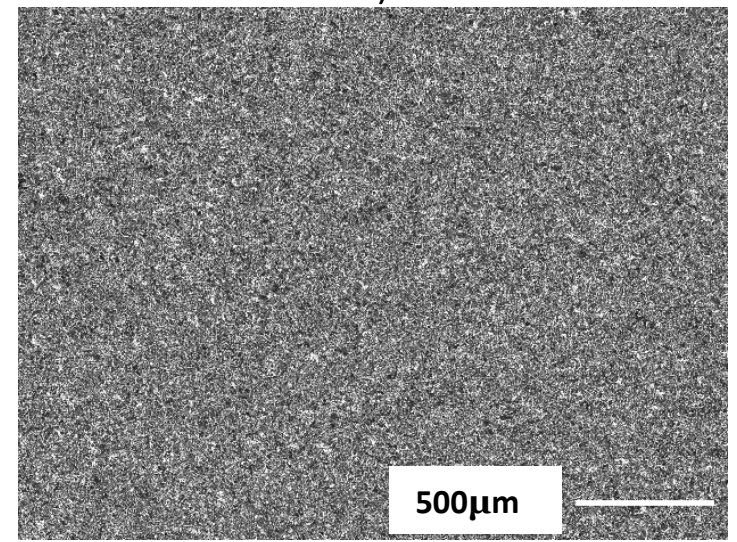

c)

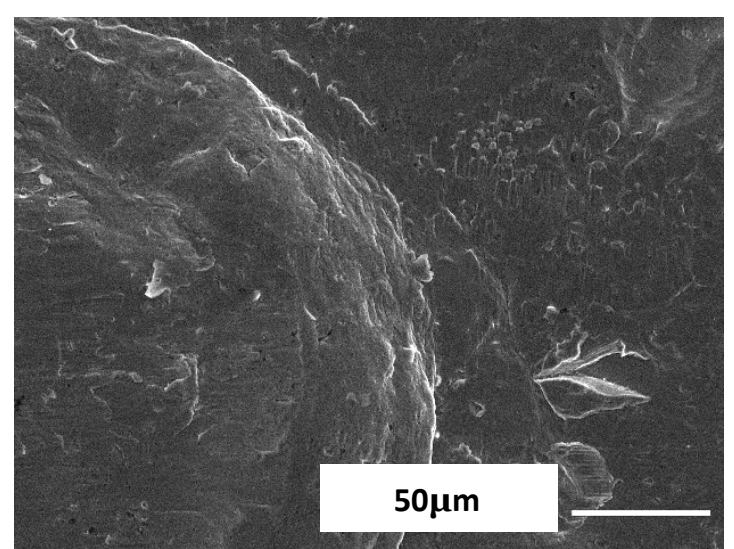

b)

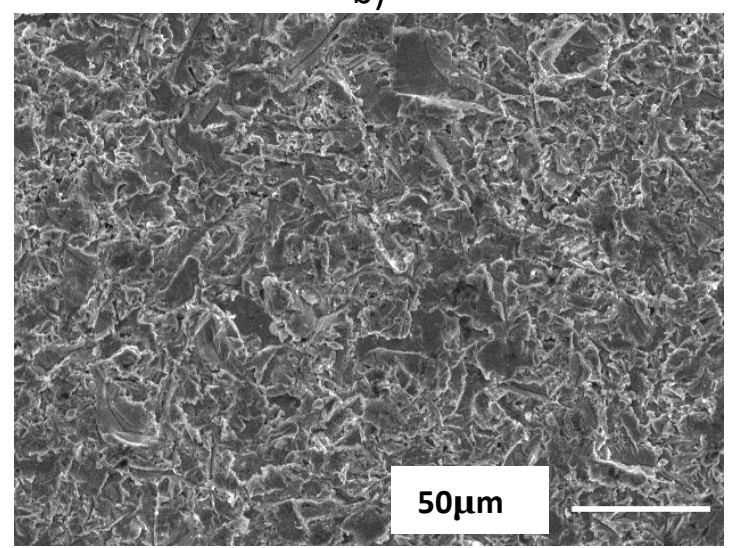

d) 


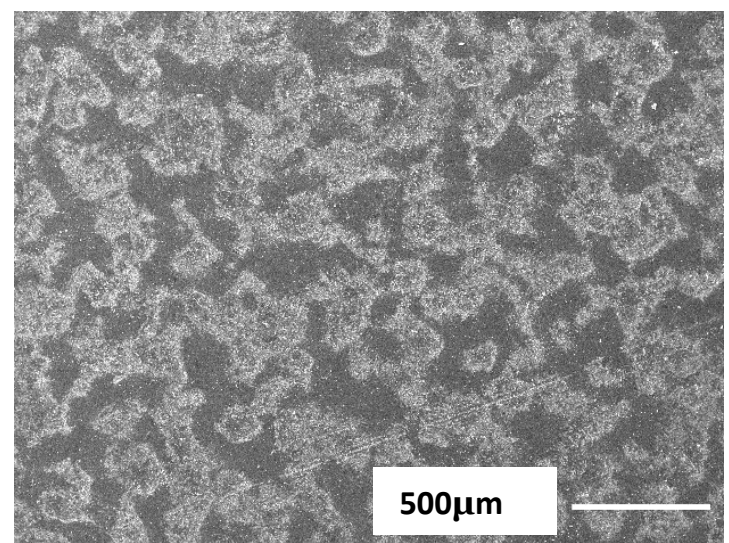

e)

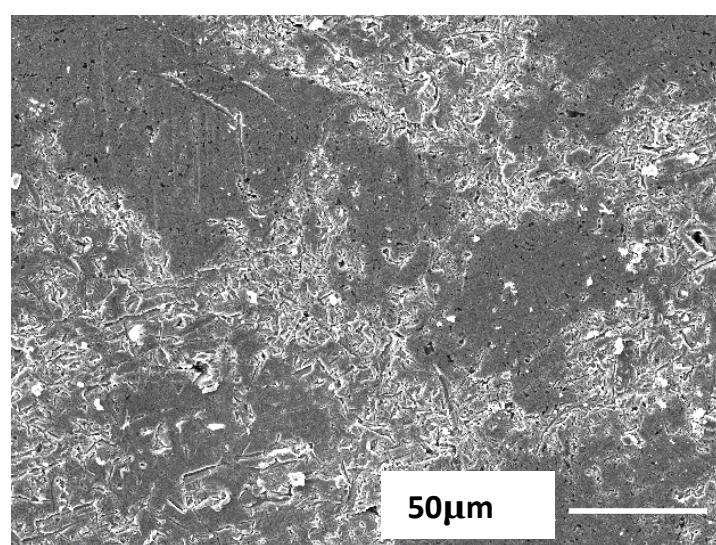

f)

Figure 8: Surface topography of surface treated samples : $a$, b) SP 19A; c, d) SP $19 A+G B ; e, f) S P 19 A+V F$

The compressive residual stress induced after the optimized double treatments is able to avoid crack propagation on the surface region, consequently triggering an internal fatigue crack growth process. In these cases, the amplitude of the stress intensity factor, $\Delta K$ (the factor directly related with the fatigue crack growth rate), acting on the largest surface defect, provided by the effective stress $\left(\sigma_{e}\right)$, which is the sum of the applied $\left(\sigma_{a}\right)$ and the residual $\left(\sigma_{r}\right)$ stresses, was lower than the stress intensity range threshold of the steel product, $\Delta \mathrm{K}_{\mathrm{th}}$, and crack growth from the surface does not take place. Nevertheless, at a certain depth, the residual compressive belt is surpassed, the compressive residual stress decreased to a non-significant value, and the amplitude of the stress intensity factor acting on the largest inclusion present in the subsurface region can surpass $\Delta K_{\text {th }}$ even under a lower local alternating stress. Figure 9 shows the residual stress profile, $\sigma_{r}$, and the magnitude of the applied alternating stress, $\sigma_{a}$ (it varies linearly with depth from a maximum located in the surface), along with crack growth criteria, acting at a surface defect and at an internal inclusion [28].

Following this analysis, it is thus possible to state that the so-called internal fatigue damage mechanism is non-dependent on surface characteristics, depending mainly on the steel cleanliness, specifically on the existence of microstructural stress concentrators such as alumina or other types of hard non-metallic inclusions. 


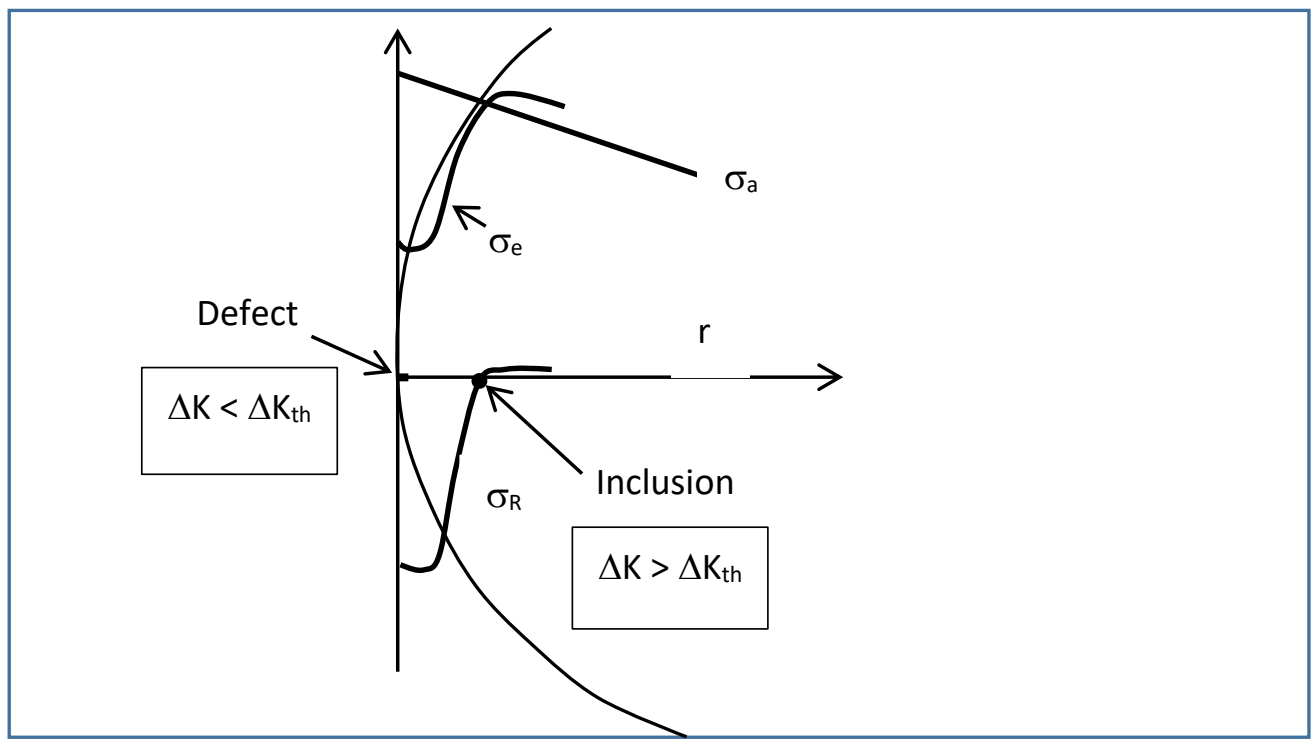

Figure 9: Stresses evolution with depth in shot peened specimens submitted to fatigue bending. Conditions for internal fatigue crack initiation. $\sigma_{e}=$ effective stress, $\sigma_{a}=$ applied stress, $\sigma_{R}=$ residual stress $\left(\sigma_{e}=\sigma_{a}+\sigma_{R}\right)$

All the fatigue specimens tested after high intensity $19 \mathrm{~A}$ shot peening followed by grit blasting for $60 \mathrm{~s}$ had a fatigue life greater than $700000 \mathrm{cycles}$ and the initiation of the fatigue crack was always internal (see Figure 6). In the case of shot peening along with a vibratory finishing of 24 hours, only two out of the five tested specimens showed internal fatigue crack initiation (both specimens also endured around 700000 cycles). The other three specimens of this lot (with a significantly lower fatigue life) showed fatigue crack initiation on the specimen surface. In this case, the second treatment was not able to completely remove all the shot peening defects, even though the lowest roughness values were obtained using this technique, as the removed damaged surface layer was $60 \mu \mathrm{m}$, instead of $70 \mu \mathrm{m}$ for the best double treatment (SP 19 A+GB60s). It is estimated that vibratory finishing should be prolonged for a longer time in order to completely remove shot peening defects. However, treatments lasting more than 24 hours were not considered suitable from a practical and economic point of view.

\section{Conclusions}


Double surface treatments, comprising a high intensity peening treatment followed by vibratory finishing or grit blasting as a second surface treatment proved to be highly suitable for enhancing the fatigue performance of high strength structural steels, as these second treatments were able to remove the damaged surface layer produced in the first high intensity shot peening treatment. A progressive increase in fatigue life with the duration of the vibratory finishing treatment was evidenced: the 24 hours vibratory treatment was able to increase the average fatigue life of the single shot peened samples almost sevenfold. In the case of grit blasting, the fatigue life increases with increasing duration of this treatment until a maximum is attained for the $60 \mathrm{~s}$ grit blasting treatment. This second treatment gave rise to a twelvefold increase of the average fatigue life of the single shot peened treatment, being the best option to enhance the fatigue life of this steel grade.

Grit blasting was found to be more efficient second treatment than vibratory finishing, as the optimization of the latter technique requires a much longer duration (more than 24 hours), while the best grit blasting treatment requires only 60 seconds.

In the case of the optimal double treated specimens giving rise to the longest fatigue lives, fatigue crack initiation took place below the surface, although the maximum applied stress in our fatigue experiments always acted on the specimen surface. The location of fatigue crack initiation corresponds to a depth at which the residual compressive stress was reduced to almost zero and took place due to the stress concentration provided by the presence of hard, non-deformable alumina inclusions.

\section{Acknowledgments}

The authors would like to thank to the Principado de Asturias government for the financing support given to the IDI/2018/000134 project.

\section{References}

[1] MFN, Shot peening. A dynamic application and its future. Metal Finishing News, Switzerland, 2009 
[2] MIC, Shot Peening: Applications, $8^{\text {th }}$ ed, Metal Improvement Company, USA, 2001

[3] SAE, Manual on Shot Peening, SAE International, Warrendale, USA, 2001

[4] S. Tekeli, Enhancement of fatigue strength pf SAE 9245 steel by shot peening, Mater. Lett., 2002, 57, p 604-608

[5] J. Almen and J.P.H. Black, Residual stresses and fatigue in metals. Mc-Graw-Hill, Toronto, Canada, 1963

[6] V. Llaneza and F.J. Belzunce, Optimal shot peeening treatments to maximize the fatigue life of quenched and tempered steels. J. Mater. Eng. Perform., 2015, 24, p 28062815

[7] M.A.S. Torres and H.J.C. Voorwald, An evaluation of shot peening, residual stresses and stress relaxation on the fatigue life of AISI 4340 steel, Int. J. Fatigue, 2002, 24, p 877886

[8] M.L. Aggarwal, R.A. Khan and V.P. Aggarwald, Influence of shot peening intensity on the fatigue design reliability of $65 \mathrm{Si} 7$ spring steel, Indian J. Eng. Mater. Sci., 2005, 12, p $515-520$

[9] Y.K. Gao, Fatigue limit of chemical heat treated specimens and effect of shot peening, Surf. Eng., 2008, 24, p 322-326

[10] A.T. Vielma, V. Llaneza and F.J. Belzunce, Effect of coverage and double peening treatments on the fatigue life of a quenched and tempered structural steel, Surf. Coat. Technol., 2014, 249, p 75-83

[11] N. Kawagoishi, T. Nagano, M. Moriyam and E. Kondo E., Improvement of the fatigue strength of maraging steel by shot peening, Mater. Manuf. Process., 2009, 24, p $1431-$ 1435 
[12] R. Selvabharati and R. Muralikannan, Influence of shot peening and plasma ion nitriding on tensile strength of 2205 duplex stainless steel using A-PAW, Mat. Scie. \& Eng. A, 2018, 709, p 232-240

[13] B.G. Scuracchio, N. Batista da Lima and C.G. Shöen, Role of residual stresses induced by double peening on fatigue durability of automotive leaf springs, Mater. Des., 2013, 47, p 672-676

[14] G.H. Farrani and H. Ghadbeigi, An investigation into the effect of various surface treatments on fatigue life of a tool steel, J. of Mater. Process. Technol., 2006, 174, p 318324

[15] K.T. Cho, K. Song, S.H. Oh, Y.K. Lee and W.B. Lee, Surface hardening of shot peened H13 steel by enhanced nitrogen diffusion, Surf. Coat. Technol., 2013, 232, p 912-919

[16] D. Wu, C. Yao and D. Zhang, Surface characterization and fatigue evaluation in GH 4169 superalloy: Comparing results after finish turning, shot peening and surfaced polishing treatments, Int. J. Fatigue, 2018, 113, p 222-235

[17] C. Yao, D. Wu, L. Ma, L. Tau, Z. Zhon, J. Zhang, Surface integrity evaluation and fatigue evaluation after milling mode, shot peening and polishing mode for TB6 titanium alloy, App. Surf. Scie., 2016, 387, p 1257-1264

[18] ASTM E466, Conducting constant amplitude axial fatigue tests of metallic materials, Annual book of ASTM standards, Vol. 03.01, ASTM, Philadelphia, USA, 1990

[19] SAE J442, Test strip, holder and gage for shot peening, SAE International, Warrandale, USA, 2008

[20] SAE J443, Procedures for using standard shot peening test strips, SAE International, Warrandale, USA, 2003

[21] P.S. Prevey, X-ray diffraction residual stress techniques, in Volume 10, Materials Characterization, Metals Handbook, ASM International, OH, USA, 1986 
[22] NPL, Determination of residual stresses by X-ray diffraction, Document No. 52, National Physical Laboratory, UK, 2005

[23] J. Kritzler and W. Wübbenhorst, Inducing compressive stresses through controlled shot peening, in Handbook of residual stresses and deformation of steel, ASM International, Materials Park, OH, USA, 2002

[24] I.C. Noyan and J.B. Cohen, Residual stress: Measurement by diffraction and interpretation, MRE, Springer-Verlag, New York, 1987

[25] D.L. Sikarskie, On a series form of correction to stresses measured using X-ray diffraction, AIME Trans., 1967, 239, p 508-577

[26] M.G. Moore and W.P. Evans, Mathematical correction for stress in removed layers in X-ray diffraction residual stress analysis, SAE Trans., 1958, 66, p 340-345

[27] V. Llaneza and F.J. Belzunce, Study of the effects produced by shot peening on the surface of quenched and tempered steels: roughness, residual stresses and work hardening, App. Surf. Scie., 2015, 356, p 475-485

[28] E. Segurado, F.J. Belzunce and I. Fernández-Pariente, Effects of low intensity shot peening treatments applied with different types of shots on the fatigue performance of a high-strength steel, Surf. Coat. Technol., 2018, 340, p 25-35. 